Journal of Management Development, 2008, Volume 27, Issue 9, Pages 912-934

\title{
Aligning business leadership development with business needs: the value of discrimination
}

\author{
Catherine Bailey, Cranfield School of Management, Cranfield, UK \\ Martin Clarke, Cranfield School of Management, Cranfield, UK
}

\section{Corresponding author}

Catherine Bailey can be contacted at: c.bailey@cranfield.ac.uk

\begin{abstract}
Purpose - This paper is derived from a two-year study that sought to provide a critical understanding of the current state of business leadership development (BLD) and to identify directions for innovative future practice. The first of two companion papers, this contribution aims to examine the issue of achieving business relevance in BLD and the quality of $\mathrm{HR} /$ management development strategy formulation.
\end{abstract}

Design/methodology/approach - The paper analyses four organisation case studies of BLD strategy derived from interview data sourced from 103 senior line/HRD managers in 20 organisations.

Findings - The findings highlight the need for HRD managers to take a discriminating approach to linking BLD strategy, development method, evaluation and the role of management development. In particular, the cases studied reflect the importance of informal activity and politics in the execution of BLD and the positive effect of individual leadership in moderating the effectiveness of the linkages between business context, BLD strategy and its implementation.

Practical implications - The paper provides a conceptual framework to enable practitioners to discriminate between different bundles of development practices that can, over time, be translated into behaviours that suit the changing needs of an organisation. A list of useful starting points is provided for managers to review and improve BLD strategy and practice in their own organisation.

Originality/value - The paper provides a framework that shows the importance of different development populations, different sponsors, interest groups and strategic timeframes in enabling more informed discussion about the strategic alignment of BLD.

Article Type: Case study

Keyword(s): Integration; Leadership; Organizational politics; Human resource development; Management strategy. 
In an increasingly turbulent and competitive environment the issues of recruiting, keeping and developing people with the capability to lead and manage business strategy are the focus of considerable attention from organizations, academics and government alike (see Williams, 2001; Council for Excellence in Management and Leadership (CEML), 2001; Sung and Quinn, 2005; Mabey, 2005). The predictable growth in leadership development activity has been accompanied by a wealth of best practice advice on how to design and implement effective leadership development (see, for example, Lee, 1996; Zenger et al., 2000; Cacioppe, 1998; Ready and Conger, 2003). Much of this advice is encapsulated by Fulmer and Wagner (1999) in eight principles: aligning leadership development to business strategy; developing an HR and business partnership; using competency frameworks; developing home grown talent; forging strong links to succession planning; encouraging action learning; ensuring high level support for development activity; and, comprehensive evaluation of outcomes. However there are evident difficulties in implementing these ideas in practice (Gratton et al., 1999; Ogbonna and Whipp, 1999; Truss, 2001).

Criticisms of current practice indicate; poor evaluation of outcomes (Axel, 1999; Mabey and Thomson, 2000; Santos and Stuart, 2003; Preskill and Lackey, 1999); the over use of competency frameworks (Hayes et al., 2000; Conger and Xin, 2000); and concerns about $\mathrm{HR} / \mathrm{MD}$ managers ability to influence the business and to take a strategic overview (Guest and King, 2004; Meldrum and Atkinson, 1998; Tate, 2004; Thomson et al., 1997). These specific criticisms reflect a wider specialist debate (Ogbonna and Whipp, 1999) concerning the overall strategic integration between HRM and the business, the complexities of which are summarised in Colbert (2004). In short, this discourse focuses on the relative value of: vertical fit, integration between business and HRM strategy (Schuler and Jackson, 1987); horizontal integration, bundling HRM activities and process to create synergies (Baird and Meshoulam, 1988); and "flexibility" of response over time, (Wright and Snell, 1998; Gratton et al., 1999; Truss, 2001). More recently, Colbert (2004) extended this latter approach to accommodate a complexity perspective in which HRM strategy is conceived in terms of enabling organizations to constantly co-evolve with their environment.

Notwithstanding this potential insight, Sheehan (2005) notes that we are still some way from realising strategic integration of HRM in practice. Not surprisingly this problem is seen as critical in the domain of management development (House and Aditya, 1997; Mabey and Thomson, 2000; Ready, 2004; Mabey, 2005). Moreover, with insufficiently rigorous data on the effectiveness of leadership development approaches, the relative strategic impact of development activities remains an area of conjecture (Fiedler, 1996; Mabey, 2002). So, is best practice advice fundamentally flawed or is it simply in need of refinement or contextualisation?

This question marked the starting point of a two-phase research project to provide a critical understanding of the current state of business leadership development (BLD) and to identify directions for innovative future practice. The results of phase one, based on the BLD experience in 20 UK organizations, reported in Clarke et al. (2004) and Clarke and Bailey (2002), revealed the extent to which BLD in practice is an unfocussed and extremely diffuse activity, which is not evaluated well and poorly aligned to business needs. This malaise was found to be the product of four interrelated factors:

1. Aligning BLD strategy to received HR wisdom about best practice rather than the medium/long-term business needs.

2. Lack of senior management vision for BLD. 
3. Poor quality HR thinking.

4. Differing agendas and organizational politics.

When combined, these four factors serve to create "catch 22" situations where development is fundamentally undermined by mutually limiting constraints. For example, attempts to make better organizational use of BLD are restricted when senior managers have a limited view of its value, a view that is only likely to change through their own experience of BLD.

In response to this widespread lack of coherence in approach, phase two of the research sought to understand how those involved in BLD made sense of their situation and came to decisions about strategy and action that enabled them to overcome this complex set of unfavourable circumstances. This involved an international survey of views about BLD practice and the analysis of cases of successful and innovative BLD activity identified in phase one.

The cases used in this paper allow us to explore two of the barriers to effective BLD cited previously; the issue of achieving business relevance in BLD and the quality of $\mathrm{HR} /$ management development strategy formulation. A companion contribution to Journal of Management Development (Clarke et al., 2008, uses cases to explore the other two barriers by focussing on the influence of competing political agendas on BLD and how HRD professionals work within this context.

We adopt a critical realist perspective (Bhaskar, 1974; Ackroyd and Fleetwood, 2000) in which organization, structure, culture and strategy are seen to co-exist but act independently of each other (Chia, 2002; Fairclough, 2005), as this perspective lends itself to analysing the relations between the unobservable, causal or generative mechanisms of effective BLD; the social structures, powers and relations that govern them, and their observable effects (Chia, 2002; Blaikie, 1993; Partington, 2002). Our research therefore seeks to make a contribution by identifying potential generative mechanisms that produce patterns of effective BLD, particularly in relation to achieving business relevance and strategic alignment. Also, following Buchanan (1999), these qualitative cases are presented as vehicles for personal learning; written as potential "classroom" cases we hope that they can be used to stimulate debate about the processes of strategic alignment. Using only four cases our purpose is thus exploration rather than prediction. On this basis, practical suggestions for HR/development professionals struggling to make a difference in similar situations is provided and potential areas for further research are identified.

\section{Strategic integration of BLD}

The drive for integration has become critical as management development is increasingly seen as a key lever in organization change, in embedding new organization values (Doyle, 1995) and improving business performance (Mabey, 2005). Yet achieving strategic relevance seems problematic.

For example, Rainbird's (1994) analysis of 21 cases revealed a lack of integration between HR and management development and the business. And several studies have found that although the main drivers of management development appeared to be strategic, development in practice is more directly influenced by individual job related requirements identified through the appraisal process and requests from line managers (Thomson et al., 1997; Cannell et al., 2000; Sung and Quinn, 2005). Mabey's (2005) recent study shows a continuing gap between management development activities and business strategy. 
The literature offers two potential reasons why management development falls short of strategic relevance: the quality of $\mathrm{MD} / \mathrm{HR}$ professionals, and the complexity of the task. While a number of studies highlight concerns about the quality of HR professionals in general (Sheehan, 2005; Guest and King, 2004), Meldrum and Atkinson's (1998) study of management development professionals in particular found line management to be largely ambivalent or negative about the organizational influence of HR professionals, their ability to act as good role models, to match needs to developmental activities, and, significantly, in terms of their strategic overview of the business.

Concerns about the quality of training and development thinking have been voiced by Mole (1996), Tate (2004) and by Thomson et al. (1997) in their study of over 900 organizations:

... there was not a great deal of evidence of deep thinking about management development, either in learning processes or in respect of an operational model or in how to link it to organizational strategies (Thomson et al., 1997, p. 79).

On this basis alone it is perhaps not surprising that the application of "best practice" approaches to strategic alignment, such as; gaining senior management buy-in (Fulmer and Wagner, 1999; Sung and Quinn, 2005); working on real projects that link to key organizational issues (Zenger et al., 2000; Ready and Conger, 2003); and, developing incompany programmes that concentrate on live organizational issues (Conger and Benjamin, 1999; Zenger et al., 2000), may well be difficult to achieve. However there is also evidence that the principles themselves may need refinement.

For example, obtaining senior management buy-in implies a degree of organizational order and rationality that may not reflect organizational reality (Francis, 2002; Skinner and Mabey, 1997). In today's environment where organizations increasingly resemble fragmented market places of competing and mutual interest groups (Colbert, 2004; Butcher and Clarke, 2001) it is often difficult to obtain collective agreement about an activity perceived to be of doubtful value when set against short-term priorities (Sung and Quinn, 2005).

While it is apparently accepted wisdom that in-company development programmes are most cost-effective and fit better with the development of strategic leaders (Conger and Benjamin, 1999; Sung and Quinn, 2005) and public or open development programmes "tend to have little impact on a leader's ability to produce better results" (Zenger et al., 2000, p. 27), studies of evaluation practices question the bases for these conclusions (Axel, 1999; Mabey and Thomson, 2000; Santos and Stuart, 2003; Sung and Quinn, 2005). Cairns (1997) for example found that half of the evaluations of open executive programmes focussed on immediate post programme effects and only 6 per cent evaluated the effectiveness after one year. For incompany programmes, only 18 per cent assessed impact one year later. Furthermore, while in-company activities potentially provide greater scope for projects that are relevant to both individual and strategic intent, these action learning projects contain inherent shortcomings such as "learner defensiveness" (Hardingham, 1999), lack of external strategic thinking and deep transformational learning (Conger and Xin, 2000).

These issues formed the background to phase two of this study in which we sought to identify case studies that would highlight factors that seem to enable effective BLD strategy formulation and implementation and reveal how HR/MD professionals tackle the complexities of strategic integration in practice. 


\section{Research methodology}

\section{Phase one}

The case studies reported in the following were derived from the phase one research, which was designed to explore the potential gaps between BLD theory and practice, strategic intent and practical experience of BLD. From a relativist perspective, phase one reflected the "empirical" phase of our enquiry, to produce a critical description of what is known about BLD (Blaikie, 1993). For the critical realist, gaining access to reality is considered problematic (Easterby-Smith et al., 2002) and in consequence our design sought to access a broad range of perspectives. This sample consisted of interview data from 103 managers in 20 organizations that were selected to represent a broad cross section of industries, size and included several multinational enterprises. The generalisability of findings was checked by a postal questionnaire representing a further 87 managers from companies in Europe, Africa and the Far East.

In response to criticism of HRM studies that rely on single HR responses (Purcell, 1999; Truss, 2001; Schneider et al., 2003) and in line with a relativist perspective that recognises competing claims about the nature of the social world and thus the likelihood of finding "supporter's opponents and doubters" (Pettigrew, 1990), four different organizational perspectives were explored to permit a level of triangulation; senior business managers, BLD recipients, $\mathrm{HR} / \mathrm{MD}$ managers responsible for BLD strategy and those responsible for BLD provision.

One-hour interviews were built around 20 question sets (see the Appendix) designed to surface perceptions about relationships postulated in an initial model of effective BLD. The model suggested a self-reinforcing set of relationships between; the strategic context for BLD, its drivers, BLD activity, and its perceived impact. Semi-structured interviews were used as this approach allowed exploration of the perceived relationships between the different elements. The tendency for socially desirable responses was minimised by assuring confidentiality and anonymity (Johnson and Johnson, 2002). Validity was further enhanced by encouraging anecdotal illustrations of responses, as these can reveal tacit thinking and organization activities not easily surfaced through other methods (Ambrosini and Bowman, 2002).

Interviews were recorded, transcribed and entered into a proprietary database management tool. Results were analysed by total sample, by organizational role, and within-company, the collection of four different perspectives allowing us to triangulate responses to further enhance validity. An organization focus to early questions served to ensure that personal experiences could be understood in context, and thus reduce any tendency to make simplistic assumptions about cross sample generalisability (Johnson and Johnson, 2002).

Responses were content analysed using standard practices for qualitative data such as those described by Miles and Huberman (1994); Milliken et al. (2003). To increase reliability, data were initially analysed separately by research team members and final coding constructs refined as a result of further cross team discussion. Results are reported in Clarke et al. (2004) and Clarke and Bailey (2002).

\section{Phase two}

Given the lack of coherence found between BLD strategy and implementation, Phase Two was designed to identify a range of solutions or "rational explanations" (Blaikie, 1993) that 
would allow organizations to break the negative and self-perpetuating Catch 22 situations we had identified, and to develop alternative approaches to effective BLD. A case study approach was considered appropriate, as this would allow us to focus on examples of effective practice and thus better understand the generative mechanisms that impact on the connections between business strategy, leadership development and the contribution of HR/MD. In particular, it would enable us to understand the context in which individuals, acting purposely, unconsciously draw upon, reproduce and moderate existing structures, powers and relationships (Ackroyd and Fleetwood, 2000).

The cases reported in the following were identified by applying two criteria: first, to ensure that organizations were representative of current leadership development thinking, the selected cases were required to reflect a majority (at least five) of the eight principles identified by Fulmer and Wagner (1999). Second, we chose cases so as to illustrate the successful application of one of four distinct BLD strategies that had emerged from phase one (see Figure 1). The BLD strategy framework differentiates and defines approaches to BLD according to the nature of their content (is content corporately consistent or individualised?) and according to development population coverage (is the population targeted or inclusive?). This meta-level framework allowed us to study BLD in different environments (Pettigrew, 1990; Harrison, 2002). Rather than seeking to establish broad generalisability, it was intended that the case data would facilitate an explanation about the structure, process and generative mechanisms in these individual circumstances.

The four distinguishable approaches to BLD which we sought to illustrate are:

1. HiPo tailored - highly targeted/individualised provision - a structured approach driven by the need for succession planning that targets high potential managers through talent spotting processes and nurtures individual development through tailored activities.

2. HiPo programme - highly targeted/corporately consistent provision - groups of managers are identified and proceed through a series of planned and consistent HiPo activities based on corporate business needs.

3. Self-motivated - inclusive/individualised provision - no defined approach, development is open to all but dependent on an individual's own motivation and skill in making things happen for themselves.

4. Generic programme approach - inclusive/corporately consistent provision corporate wide programmes to develop/ improve specific organization capabilities, often cascaded down through different levels of management.

Although not mutually exclusive approaches, as some organizations employed more than one approach in different divisions, we concentrated on a particularly successful example of each to highlight four very different, yet valuable BLD strategies and to describe why and how each was found to be effective for the business context in which it was adopted. The intent was to explore how strategic alignment can be achieved, to provide comparative information on development strategies and to offer ideas about alternative approaches. 


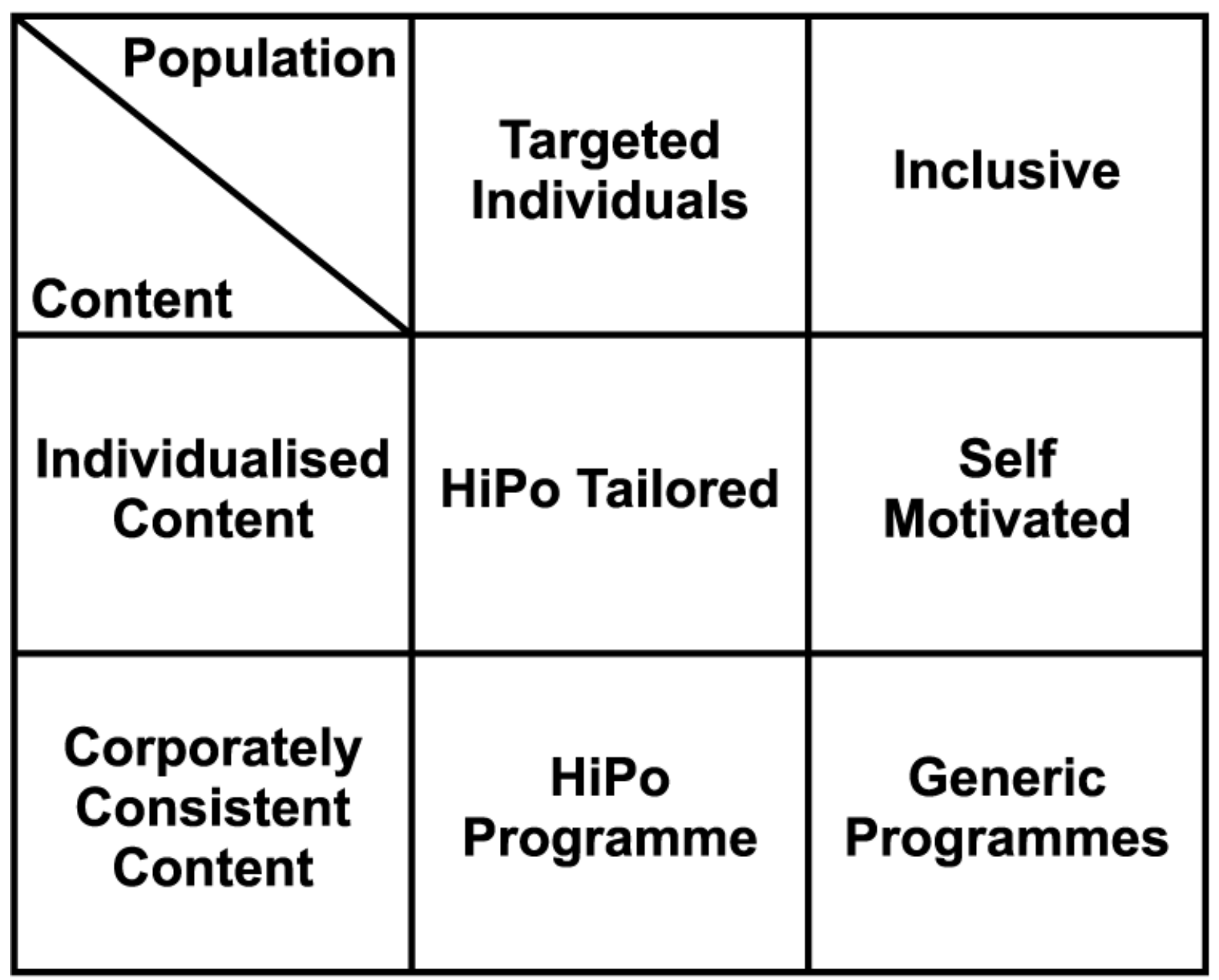

Figure 1BLD strategy framework

The four case organizations reported here are: BANKCO, SOFTCO, PARCELCO and RETAILCO. Commensurate with a relativist ontology, the Phase One design sought to explore multiple perspectives through a corroborative design based upon five to six interviews from different organizational perspectives. These data were supplemented by additional interviews with key contacts within each business, and with publicly available data, used primarily to confirm specific details rather than add to the substantive content.

Initial pattern codes derived from the BLD Strategy Framework were used to develop interim case summaries that became the focus for case meetings among the research team. These codes were refined and a list of variables created for each case. These were used as the basis for initial causal mapping. Cross case maps were constructed using variables estimated to be the most influential in accounting for the outcomes described in each organization. These variables are discussed later in the paper. Our main HR/MD contact in each organization was given an opportunity to critique/comment on the case content. None of these observations necessitated substantive revisions.

Each case presented in the following describes the organizational context for development, the company's approach to business leadership development in relation to the BLD Strategy Framework and briefly summarises the key aspects of each. 


\section{BANKCO: HiPo tailored}

The financial services industry is still subject to enormous change. In a huge deregulated market with low barriers to entry, competition is intense, and new entrants are quick to capitalise on the blurring of the traditional boundaries between retail and investment banking and the insurance sector. For leading international players like BANKCO, this continues to be a global challenge. At the time of writing, their executives were being asked to tackle problems unimaginable ten years previously. But turning the direction of an organization of many tens of thousands of people was taking time and required a steady supply of managers who were able to think innovatively outside of their role, organization and industry.

It was this business need that formed a distinctive focus for BANKCO's approach to management and leadership development. In particular, they had been careful to distinguish between the development needs of their future business leaders and those of other managers. The bank needed leaders who were able to cope with high levels of uncertainty and ambiguity in order to be able to deliver and continue to develop its future strategy.

In consequence there were very clear development processes for the top 200 executives. Development was managed through two separate programmes; the Group Executive Resource (GER) for the top 50 managers and the Top Management Resource (TMR) for the next 150 high potential managers. These populations were nurtured by an eight person executive resourcing team. Donal, who led the team, believed that the business need for good succession planning was so well accepted by the board that:

... getting the time and sponsorship the team needs to carry out these programmes is not an issue.

Indeed, it was also evident that the Chief Executive saw good succession planning as a key priority for the business.

In both programmes managers attended an externally managed assessment centre where they were assessed against a limited set of bespoke competencies that reflected the senior management capabilities required by the business, given its history, culture and future aspirations. These included new behaviours for the bank such as "restless curiosity", the ability to take an external perspective and to successfully bring that inside BANKCO and the ability to build good relationships, not just with peers and team members but also in partnerships, joint ventures and with suppliers. While many of these competencies were relatively new to the bank, importantly they were viewed as changeable. As Donal pointed out,

... these are designed to take us into the future but they may well need to be reviewed in two or three years time to ensure we stay ahead of the game. The model is a fluid living thing and will need to develop over time.

Following initial assessment individual development was tailored according to each senior manager's requirements. Each person in the GER had their own "account manager" from within the executive resourcing team to ensure that resources and opportunities were optimised. The range of activities available was wide. Managers could attend external programmes at well-known business schools and participate in one-to-one coaching with external coaches. They would have an internal mentor, usually a company director and receive regular 360-degree assessments and carefully selected job moves. They could also 
attend business consortia programmes to rub shoulders with peers from other leading organizations and were encouraged to network to share their insights and know-how.

At the point of data collection it was relatively early days to measure the effectiveness of this approach and there was some debate as to the most appropriate measures. However, the metrics that were being used focussed on what the bank called "talent flows," the number of career moves by the GER group across, and up through the hierarchy, and recruitment and retention rates for this high potential population. Consideration was also given to senior executive and GER views about the quality of the talent pool. Donal was:

... doubtful as to the practicality of identifying more concrete processes of evaluating the effectiveness of the initiative, despite recent advances in human capital accounting.

Throughout our interviews with HR and line managers it was clear that both believed that such activity had a direct positive impact on current and future business performance.

This case example illustrates the HiPo tailored approach. With the huge upheaval in financial services the bank's senior management identified that succession planning was a major priority and that leadership development played a key role in preparing potential successors for the uncertainty and ambiguity of the globally competitive environment by developing the ability to work, form productive relationships and incorporate ideas from outside their business and industry. But, given BANKCO's culture, and the uncertainty about the future of the industry, attention was given to developing a new approach to leadership development, one that, in the words of one senior manager

... helps managers understand what is expected of them without being prescriptive.

This directly influenced the individualised BLD approach the company adopted. The company was highly selective about who forms the GER but not at all prescriptive about the development process. A broad range of opportunities was made available to develop these capabilities. While at the time of data collection it was still early days, the success of this approach was evident in the time and resources it received from senior management, the investment the programme attracted and the positive feedback about it from those involved.

\section{SOFTCO - HiPo programme}

In 2001 SOFTCO was a small independent software and services business focussed on niche financial applications, employing around 600 employees in the UK, the USA and Asia Pacific region. In a highly competitive market still coming to terms with the impact of ebusiness, senior managers had become aware of the need to improve SOFTCO's operational flexibility in providing cross product/service solutions for customers. There was common agreement among the senior group that the company needed to develop its ability to become more responsive to customer requirements and needed to encourage greater levels of proactivity and cross functional working in its management population. However, the company was under pressure to improve its financial performance, did not have a history of formal business leadership development and not all the senior team recognised the value of leadership development as a way of tackling these business issues. As one senior manager, Steve, remarked

... the CEO and the FD know the cost of everything and the value of nothing. 
Despite these unfavourable circumstances and the lack of a clear executive commitment, Bill the HR Development Director and some senior colleagues developed a strategy to use leadership development to tackle these critical business issues:

... in short, the strategy is to identify high potential managers who will receive shared and consistent development that focuses on knowledge sharing and innovation. These managers are being encouraged to create "pockets of good practice" to role model change for the rest of the business.

The Management Action Programme (MAP) established by Bill was developed for a limited number of high potential UK middle managers selected by the small group of senior colleagues. While this approach attracted some concerns about elitism, Bill and his colleagues considered that:

... working within tight time frames and a limited budget, and in the absence of a validated assessment tool, executive managerial judgement about those most able to benefit can be an effective approach.

On the surface, the programme content was not unusual. Its aim, in line with agreed business needs was to improve cross-functional working and equip managers to take more

responsibility to "make things happen". What was particularly noteworthy was the way in which the programme integrated personal development with key business issues. As well as providing much needed business knowledge the programme deliberately fostered a real sense of group identity to enable them to work collectively and independently to initiate change, sometimes, despite considerable organizational constraints.

Programme evaluation was predominantly anecdotal but both the target population and other senior managers noted a number of significant outcomes. For example, the participants felt they were more open with each other after the programme so that it became easier to achieve cross-functional activities. As one participant, Kevin, put it:

... we had a ready built network to help implement new ideas.

They also felt more confident, tackling difficult issues without needing to seek permission and better able to see the bigger business picture. The action learning projects resulted in the successful introduction of a new customer care strategy that led to a 200 per cent reduction in customer complaints and a corporate intranet that was believed to have substantially improved cross organizational working.

Significantly, these positive outcomes were achieved in a largely unsupportive environment and with a relatively low budget of $£ 30,000$. This illustrates what can be achieved through business leadership development activity that does not rely on top-down support and development processes. The participants were mainly middle managers and were able to initiate change from the "inside out". By working on projects that were local and important to participants and not "imposed", as is sometimes the case in such initiatives, business benefits were valued and realised. Of particular importance in facilitating this was the HR Development Director's deliberate role in both protecting the programme from interference from those less convinced of its merits and through his leadership of the development project. This leadership was demonstrated in co-presenting the programme, in coaching and mentoring, and in helping to clear the path for the business improvement projects. 
HiPo Programmes are characterised by activities that have consistent development content combined with the need to be selective about who receives that development. In this case, the HR Director and close colleagues perceived the need to initiate corporate-wide change from within and therefore selected for participation those managers they believed were capable of initiating and delivering this change and used the MAP as a vehicle for facilitating, focusing and creating mutual support for change activities. An inclusive approach would not have provided participants with the same potential and a tailored design might not have produced the same critical mass with a common focus. In contrast to BANKCO, the SOFTCO example demonstrates how targeted programmes do not necessarily require unanimous senior management approval nor do they depend on providing a wide range of non-targeted development activities to mitigate concerns about elitism. Instead, in this case, it appeared to be the personal purpose, commitment and leadership of the HR Director that helped make the intervention successful.

\section{PARCELCO: self-motivated}

PARCELCO is a world leader in international air express and an established innovator since it commenced operations over 30 years ago. At the time of study it employed over 68,000 people servicing 635,000 cities in 228 countries. The most substantial operation outside of the USA is in the UK.

In 2001, prompted by several factors, the organization had adopted the "self-motivated" approach to business leader development. The culture of PARCELCO had for some time given a priority to encouraging frontline management autonomy. This provided managers with the opportunity to exploit the company's traditional entrepreneurial spirit, a quality seen as particularly important in the highly competitive air express business, as well as the scope to deliver the substantial growth the company was experiencing. As the new HR Director pointed out, this had encouraged a "no nonsense, just do it approach" to the business. In consequence, PARCELCO needed managers who were self sufficient and able to work independently, and a training and development function that had a strong commercial orientation.

In this context, the format for business leader development that emerged was one in which individuals took responsibility for their own development. Such an approach can of course be open to criticism and abuse as it can have the appearance of being highly fragmented, individualistic and lacking any real strategic purpose. However, PARCELCO have been able to introduce a number of core processes that have contributed to creating an extremely positive development culture consistent with strategic aspirations of the business at that time. As one manager, Simon, described the culture:

It's easy to get the development you want, if you have a need, the organization will try and meet it.

At the heart of this strong development culture were two development centres, open to all managers according to organizational level. This, combined with a strong operational competency framework and a well-supported personal development planning process, meant the company had, as one line manager described it "the building blocks for individuals to develop themselves". The training and development department, described as "easily accessible" in terms of getting support and influential with the senior executive team, was seen as significant in creating this culture. 
Thus in practice, the PARCELCO approach at that time provided a consistent front-end assessment process from which managers at all levels could map out their own development from a wide range of activities including coaching, work assignments, mentoring, external programmes, MBA's and educational scholarships. The company provided internal programmes addressing key commercial activities. There were some development activities that necessitated greater levels of targeting but on the whole this was not as strong as the need for self-motivated development. Despite the apparent open-ended nature of the development process, the development content was usually aligned to PARCELCO's business needs as choices were based on a well regarded assessment process tied to an organization-wide competency process.

The strategic relevance and sensitivity of this choice of BLD approach was highlighted when in the face of increasing competition and a plateau in market growth, PARCELCO identified the need for enhanced operational harmonisation. With a heightened emphasis on global synergies and greater job harmonisation the development function began to play a wider role in supporting international succession planning through more corporately consistent development provision. Nevertheless, the "Self-Motivated" approach to development was still valued but driven by a wider strategic consideration. As the HR Director pointed out:

... the idea that there is no longer a job for life is really becoming a challenge for companies. Managers are asking "what's in it for me?" We need to ensure that we redress the balance by providing people with interesting jobs and development opportunities to personally grow themselves. If we can't, then they, and their knowledge, will walk out of the door.

In the self motivated quadrant, organizations are responding to the needs for an inclusive yet individualised strategy. Given the PARCELCO business model that required strong local autonomy, it was important, as one senior manager expressed, that "everyone has the opportunity to develop themselves." To give priority to targeting and corporate consistency would have been countercultural and have generated inappropriate levels of centralisation. However, by ensuring the establishment of robust selection and assessment processes, the approach avoided becoming an uncoordinated "free for all" but allowed activities to be aligned to broad business needs. The success of this approach was evident in the extremely positive way interviewees talked about PARCELCO's development culture and in their belief that they really did have the opportunity to develop both themselves and their business. Perhaps the best evidence of the effectiveness of this approach was the company's ability to sustain remarkable organic development over many years.

\section{RETAILCO: generic programmes}

RETAILCO, one of the UK's leading retailers, at the time of the study had a turnover of $£ 25$ billion and employed over 250,000 people in the UK, continental Europe and South East Asia. At the heart of this success is a business model that ensures a consistently high quality customer experience. The development of RETAILCO's culture, based on two key values, "treating people how we like to be treated" and "no one tries harder for customers", was consistent across all its activities and was, and still is, an essential part of this success. The effectiveness of such value driven business models depends on the degree to which leaders throughout their organization, role model valued behaviours. Management development has therefore had a significant part to play at RETAILCO in enabling managers to take up this challenge and embed the RETAILCO way of doing things. This also meant that leadership and management development activities were closely aligned with RETAILCO's business needs at that time. As one manager, John, put it: 
... the driver of our management development strategy is to ensure that the organization develops its capability to deliver our business goals.

In consequence, this need to develop a clear "RETAILCO Way" provided the impetus behind a whole range of corporately consistent inclusive development activities. For example, the company undertook a five-year programme to ensure that all its 8,000 managers, from the top through to first line supervision, had a common language about core managerial processes. This included skills programmes that enabled the company to adopt a consistent approach to effective meetings, to the use of rapid reaction teams, to coaching and performance feedback, to problem solving and decision-making. Despite this predominately inclusive approach some targeting did take place in recognition of the different needs of general management and business leader populations, but even then on the basis of corporate consistency. For example, the top 1,500 managers participated in a situational leadership programme and all store managers attended an in-company business school programme. Corporate inductions, special change programmes and the development of an organization-wide managerial competency framework supported these types of activities.

The success of these generic culture change programmes often lies in an organization's ability to take account of employee views about these values in action and to respond to concerns about what they see as being important. Without a real interest in employees, such processes can become overbearing and subject to considerable scepticism, a point not lost on the management development team:

I wouldn't say that our managers weren't cynical about our values at first, of course they were, but we have been careful to ensure that senior managers really do live the values we promote. Every year we undertake an employee attitude survey. This assesses different aspects of our ability to live our values. For example, by looking at employee satisfaction in areas such as personal development and performance review we can identify whether managers are really taking an interest in their staff. At the moment we have had over 80 per cent of our performance reviews completed in the last year.

This survey was supported by a balanced scorecard monitoring process that ensured the integration of people, operational, financial and customer strategies. Each quarter the process flags up where the company may be falling short on its objectives on a green-amber-red warning basis. Such methods helped ensure that management development plans did not become disconnected from the business. Other processes that helped ensure the deployment of such management development were values workshops and 360-degree appraisal processes that encouraged managers to link their objectives to the key organization values.

However, despite the success of this robust set of generic programmes RETAILCO was acutely aware of the danger of relying purely on these for future leadership growth and for the need to supplement this approach with alternative processes. As a senior development manager, Peter, explained:

We have to be on our guard against becoming too inward looking ... in the future the critical competence we will need will be change management skills and a culture of continuous improvement. The challenge is to create competency frameworks that are nimble enough to respond to rapid change. 
Furthermore, inclusive programmes run the risk of not differentiating sufficiently between leadership and management. Such approaches need a robust set of selection processes to ensure that the best rise to the top. If selection is only made on here-and-now assessments through performance appraisals, there is a danger of building a short-term focus into a BLD strategy. Additional processes are therefore required to ensure that leadership attributes that promote a longer term and more challenging view are developed.

With this in mind, the RETAILCO "Academy" was created which afforded more targeted and individualised approaches, as a vehicle for developing the next generation of RETAILCO leaders for who the challenge was to balance adherence to the "RETAILCO Way" with the need for greater innovation. As Peter put it:

... the company is now operating in nine countries outside of the UK and given the diversity of these business environments it is quite possible that we may need to get store managers to think differently if they are to fulfil our ambition to create real value for our customers.

Adopting a generic programmes approach is consistent with seeking to influence corporate culture through inclusive and corporately consistent development. Driven by a clearly articulated business need for a consistent high quality customer experience which is embedded in the value driven "RETAILCO Way", RETAILCO used this approach extremely effectively. They also worked hard to ensure that senior management really did live the espoused values and had a real interest in listening to employees, thus trying to minimise the gap between senior management rhetoric and organizational reality. An undue emphasis on targeting and tailoring would have undermined the establishment of that inclusive culture implied by "treating others as we would like to be treated ourselves". The success of the approach was not only reflected in RETAILCO's performance but in their employee feedback and positive views about their meritocratic organizational culture. However, strong cultures can become inward looking and complacent unless care is taken to inculcate a broader external business perspective. Similarly, the drive for inclusion can mean there is a danger that leadership needs become undifferentiated from more general management development. RETAILCO proceeded to focus on these very issues, demonstrating the need for a critical view of the continuing relevance of any particular BLD approach in meeting the anticipated strategic and business needs as they changed.

\section{Emerging themes}

These cases were chosen to reflect very different approaches to BLD and illustrate how different development strategies can align with different strategic, business and cultural circumstances. Our case selection method would of course lead to some common features such as developing home-grown talent, the use of competency frameworks and so on, but beyond these obvious points of similarity, what kind of "generative mechanisms" or causal powers do the case analyses surface that may help practitioners tackle the problems of achieving strategic relevance and enhancing the quality of HR/development thinking? Five substantive themes appear to be significant, each reflecting the transformational impact of individual agency in shaping the social processes and structures (Fairclough, 2005) of effective BLD.

\section{Linking BLD strategy to business need}

The importance of aligning BLD activities to business needs is now taken for granted (Doyle, 1995; Lee, 1996). Yet Phase One revealed that organizations did not find this easy to achieve (Clarke et al., 2004). Only 20 per cent of respondents were able to identify strategic drivers 
for their organization's BLD approach. Lack of clarity about BLD purpose was frequently revealed by the confusion about whether development should be for a targeted audience or inclusive of all managers and whether development content should be individually tailored or corporately consistent, provoking simultaneous complaints of elitism or unfocussed activity. And some practitioners, applying multiple strategies, were not clear about how these related to one another or how together they aligned to their organization's business needs. Finally there were frequent examples of practitioners confidently pursuing a development strategy in one framework quadrant while line managers believed their focus should be in another.

Significantly, in the case organizations a critical causal mechanism appeared to be the clarity of individual agents about their business context (Schafer et al., 2001), the major strategic issue they were trying to address and therefore the choice of approach, which would prove to be most relevant. For example, the HRD Director in SOFTCO recognised that given the scale of the change required in cross-functional working he needed to target his development population selectively but at the same time ensure that BLD content was consistent in order to achieve the critical mass required. In RETAILCO, similar insights were achieved; high levels of targeting would undermine the declared values of inclusion. While in PARCELCO inappropriate levels of corporate consistency would detract from the autonomous business model. A good understanding of their business circumstances as well as current and critical strategic imperatives thus enabled individual agents to make critical content and population judgements to ensure a high degree of relevance to their business circumstances and aspirations.

\section{Linking development method to business need}

A key driver for leadership programmes is often the need to build a common approach and network among senior managers (Kamoche, 2000). Combined with prescriptions to develop home grown talent through action-learning, and a view that in-company programmes provide a better fit with the development of strategic leaders (Conger and Benjamin, 1999) and that public programmes tend to have little impact on a leader's ability to produce better results (Zenger et al., 2000), it is not surprising that internal programmes are popular.

These cases however highlight how some individuals are moderating such "taken for granted" assumptions and are not restricting themselves to such an internal or inclusive approach advice. Instead they are using agreed perceptions about business need as the rationale for the development approach. For example, in BANKCO senior management are using external development activities for selected individuals to stimulate the development of an external perspective in an organization that had been traditionally inward looking. This suggests that these selected managers are seen to have the potential personal influence to modify existing social processes that encouraged BANKCO'S introspection. RETAILCO also recognise the risks of developing an inward looking culture and their need to inculcate a broader external perspective. However, in contrast to BANKCO, this organization emphasises the use of formal structures such as a leadership academy, competency framework, and vision and value statements to both reinforce and modify existing managerial practices. In PARCELCO the drive for local autonomy and entrepreneurial spirit meant that corporate consistency was not essential and external development activities had a potential value in modifying existing structures by stimulating broader and innovative business thinking. The PARCELCO case is supportive of Mabey's (2002) finding that when responsibility for development is given to individual managers there is a corresponding increase in diverse development activity. 


\section{Clarity about the role of management development}

In our initial survey although we found many MD practitioners who had great clarity about the role of management development and how it aligned with different business drivers, these plans were often not well communicated to their internal customers, a point echoed about HR in general by Guest and King (2004). Consequently line managers tended to see a raft of seemingly unconnected development activities and were unsure how their own needs were being managed. This underlines the need for clarity about the vision for management development in addressing these issues and about how best to communicate this role.

In contrast to earlier criticisms of the ability of development practitioners to lead change (Mole, 1996; Thomson et al., 1997) it was apparent that in each of these cases, practitioners were challenging existing definitions of the relevance and role of BLD. For example, Bill in SOFTCO was prepared to generate change from the following in the absence of senior management appreciation of and investment in development. In BANKCO, Donal introduced senior management competencies that challenged existing conceptions of leadership, and in RETAILCO, Peter and his colleagues are rethinking the future competencies of a more international RETAILCO.

With regard to communicating this role, in our cases this was done better than most, but still with room for improvement. Processes varied from BANKCO's use of internal corporate communications via the internet and brochures, to Bill's very personal approach in SOFTCO. In RETAILCO the balanced scorecard provided employees with information about how annual people development initiatives contributed to the overall business.

\section{A discriminating, strategically based approach to evaluation}

Surveys repeatedly report the inadequate assessment of development activities (Axel, 1999; Thomson et al., 1997; Council for Excellence in Management and Leadership (CEML), 2001). Lack of clear objectives and the difficulty of establishing quantifiable results have been cited as significant reasons (Cairns, 1997). In our cases the organizations evaluated the results of their investment and overcame some of the reported problems, once again by taking a more discriminating approach. In BANKCO the focus on creating a stock of high potential managers enabled the HRD team to evaluate their work through business-wide measures related to talent flows. In SOFTCO the significant measures were again a reflection of the development goals; perceived improvements in cross-functional working, pro-activity and customer service. The drive for corporate alignment in RETAILCO has led to a range of business outcome measures such as attitude surveys and balanced scorecard evaluations. In each case, selecting measures appropriate to strategic intent surmounted the perennial problem of evaluation. In turn, this differentiated approach forced and enabled better quality of thinking in those responsible for BLD.

\section{Individual leadership in BLD}

The Catch 22 situations that surround BLD in many organizations leave management development professionals trying to initiate BLD in extremely unfavourable circumstances. Yet success in these case studies appeared to be closely related to one or more people taking a substantive leadership role in the design and implementation of BLD. In particular, the illustrative examples reflect the importance of individual agency in influencing the establishment of a strategic focus. This is supportive of other research (Murphy and Southey, 2003) about the role of leadership in HR innovation, but suggests that agents can make progress even when legitimate organizational support is lacking. For example, in SOFTCO, BLD itself was used to challenge dominant definitions of the way the organization worked. 
Bill's vision, acknowledgement of different power bases and challenge were central to overcoming the complex set of political and institutional barriers that beset the BLD arena. This is supportive of Truss's (2001) observation of the criticality of informal processes in implementing effective HRM and, Ogbonna and Whipp's (1999) view as to the inherently political nature of the connections between strategy and HR. The kind of leadership displayed in these cases provides an initial insight about how it is that individuals can make a difference to the effectiveness of BLD in the face of unfavourable circumstances. We illustrate this critical area in detail in the companion paper (Clarke et al., 2008).

\section{Points for reflection and action}

We believe this analysis builds on current literature in several ways. In recent years there has been considerable debate about the relative value of; vertical and horizontal integration between business and HRM strategy; and the need for "flexibility" of response over time (Wright and Snell, 1998; Purcell, 1999; Gratton et al., 1999; Truss, 2001; Buyens and De Vos, 2001). We believe the BLD Strategy Framework described here adds to this debate by providing a conceptual tool that synthesises concerns for both fit and flexibility considered critical by Wright and Snell (1998) and Purcell (1999). The bottom two quadrants being concerned with organizational consistency explicitly address issues of vertical fit, while the top two quadrants offer opportunities for flexibility in as much as they are designed to specifically enhance behavioural repertoires that can provide organizations with options for pursuing strategic alternatives (Wright and Snell, 1998, p. 761). Indeed this formed part of the driving force behind the PARCELCO and BANKCO approaches.

The model can therefore be viewed as a tool to help ensure that BLD is concerned with "ensuring fit among a subset of strategically relevant variables while simultaneously seeking to build generic organizational capabilities that can be applied toward both discovering and implementing a variety of diverse strategic initiatives" (Wright and Snell, 1998, p. 767). This is achieved by helping those responsible for BLD to discriminate between a bundle of practices (not a definite list) that highlight how, over time, BLD processes can be translated into behaviours that suit the changing needs of an organization (Purcell, 1999). We argue therefore that explicit recognition of different development populations; different sponsors, interest groups and strategic timeframes will form the basis for a more informed discussion about strategic alignment of BLD. This broadly allies with Delery and Doty's (1996) "configurational" approach to HR practice. While the Strategy Framework may understate the real world complexity of organizational possibilities (Colbert, 2004) in only providing four possible configurations of BLD, it is not our intention here to replicate all possibilities or create ideal types but to draw attention to some of the key variables to consider in operationalising BLD.

Indeed, in Mabey's (2002) study, four key variables in UK management development practice are highlighted; the corporate context, the decisions made about development choices, the content and extent of the development activities and the qualitative value attached to the investment in management development. Although all four of these variables and the linkages between them are reflected within our own five themes, the cases also reflect the importance of informal activity, individual agency and politics in their execution (Truss, 2001; Ogbonna and Whipp, 1999; Sheehan, 2005). The individual clarity, motivation and leadership of those championing BLD considerably moderated the effectiveness of the causal linkages between business context, BLD strategy and execution. Indeed, it may well be this individual orientation that enabled these organizations to work through the inevitable ambiguities and contradictions of HRD policy (Ogbonna and Whipp, 1999; Guest and King, 
2004). By mobilising relationships, power resources and structures to challenge the enactment of BLD, agents were able to "transform" the structures of BLD to achieve levels of BLD coherence.

In combination, the five themes explored here appear to generate a level of discriminative thinking that results in a differentiated approach to BLD. In each case this enabled the organization to overcome many of the issues of relevance, vision, power and quality identified through the initial survey, particularly those of strategic relevance and quality of thinking. These themes and linkages therefore do not provide the complete answer, but do surface a number of helpful themes for HR/development professionals to consider. For example, thinking more acutely about the relationship between business need/context, target population and development method forces better quality thinking about BLD strategy. This clarity of intent can form the basis for challenging existing approaches and developing a more effective business role for BLD.

These insights suggest useful starting points for management development specialists and senior managers in reviewing and improving the BLD strategy and practice in their own organizations.

1. Are we clear about where our current BLD strategy sits in this matrix?

2. Are we clear about which business conditions support that position?

3. Are we therefore able to demonstrate a real payback to the business?

4. Which set of factors (corporate consistency, individualisation, targeting, inclusion) is most important for meeting current business needs?

5. Do different business units/activities/levels/management populations require different approaches/development methods?

6. How well are these plans communicated to the different management populations so that they understand how their different needs are being managed?

7. How will anticipated changes to the business influence the future positioning of our approach in this matrix?

The case studies were prompted by our earlier findings that exposed the extent to which BLD is a poorly understood activity, often disconnected from business needs and greatly underutilised as a means of improving business performance. By definition, case studies provide a limited sample and our intention here was to stimulate debate about effective processes of strategic alignment rather than provide highly generalisable insights. However, what emerges from the analysis is the importance of developing a more discriminating approach to BLD one that acknowledges the criticality of vision, business relevance, politics and quality thinking in ensuring a strategically integrated and effective approach.

This analysis also raises further questions. First, although part of a larger international sample, all the cases focussed on the UK context, albeit that three are part of international corporations. Would effective approaches to alignment differ in a different cultural context? Second, neither do the cases provide detailed evidence about the relative effectiveness of different development methodologies. Are there any development methods that are more appropriate in different quadrants of the BLD strategy framework? Third, in contradiction to "best practice" advice, organizations are successfully using both internal and external methods of development, so what is the relative value of internal and external activities for BLD? Fourth, one of the most significant barriers to a coherent strategic approach to BLD identified through our research was the lack of a meaningful senior management vision for 
BLD. Perhaps one of the most important questions that needs to be researched is how senior management view the relative value of leadership and therefore business leadership development against other potential drivers of business performance improvement such as brand, product development or culture. Until greater certainty about these relationships can be obtained, widespread progress on the impact of BLD may be limited. As long as this is the case, as practitioners we are forced to ask how individuals leading BLD can really make a difference now? This question is the focus for the companion paper (Clarke et al., 2008).

\section{References}

Ackroyd, S., Fleetwood, S. (2000), "Realism in contemporary organisation and management studies", in Ackroyd, S., Fleetwood, S. (Eds), Realist Perspectives on Management and Organisations, Routledge, London, pp.3-25.

Ambrosini, V., Bowman, C. (2002), "Mapping successful organizational routines", in Huff, S., Jenkins, M. (Eds),Mapping Strategic Knowledge, Sage Publications, London, pp.19-39.

Axel, H. (1999), "Developing leaders", HR Executive Review, Conference Board, New York, Vol. 7 No.1, pp.1-19.

Baird, L., Meshoulam, I. (1988), "Managing two fits of strategic human resource management", Academy of Management Review, Vol. 13 No.1, pp.116-28.

Bhaskar, R. (1974), A Realist Theory of Science, Leeds Books Ltd, Leeds.

Blaikie, N. (1993), Approaches to Social Enquiry, Polity Press, Cambridge.

Buchanan, D. (1999), "The logic of political action: an experiment with the epistemology of the particular", British Journal of Management, Vol. 10 No.3, pp.S73-S88.

Butcher, D., Clarke, M. (2001), Smart Management: Using Politics in Organizations, Palgrave, Hampshire.

Buyens, D., De Vos, A. (2001), "Perceptions of the value of the HR function", Human Resource Management Journal, Vol. 11 No.3, pp.70-89.

Cacioppe, R. (1998), "An integrated model and approach for the design of effective leadership development programs", Leadership \& Organization Development Journal, Vol. 19 No.1, pp.44-54.

Cairns, H. (1997), "Study of current practice in assessing the impact of management development in international organisations", paper presented to the UNICON Conference, Creating the Future of International Executive Development Together: A Visioning Process, Lausanne, 5-7 April.

Cannell, M., Powell, M., Sung, J. (2000), "Missing link", Learning Centre, People Management, Vol. 6 No.9, pp.51.

Chia, R. (2002), "The production of management knowledge: philosophical underpinnings of research design", in Partington, D. (Eds),Essential Skills for Management Research, Sage, London, pp.1-19.

Clarke, M., Bailey, C. (2002), "Leadership development - creating innovative future development", paper presented at the first EAISM Conference on Leadership Research, Oxford, December.

Clarke, M., Bailey, C., Burr, J. (2008), "Leadership development: making a difference in unfavourable circumstances", Journal of Management Development, Vol. 27 No.8, pp.82442. 
Clarke, M., Butcher, D., Bailey, C. (2004), "Strategically aligned leadership development", in Storey, J. (Eds),Leadership in Organizations, Routledge, London, pp.271-92.

Colbert, B. (2004), "The complex resource based view: implications for theory and practice in strategic human resource management", Academy of Management Review, Vol. 29 No.3, pp.341-58.

Conger, J., Benjamin, B. (1999), Building Leaders: How Successful Companies Develop the Next Generation, Jossey Bass, San Francisco, CA.

Conger, J., Xin, K. (2000), "Executive education in the twenty-first century", Journal of Management Education, Vol. 24 No.1, pp.73-100.

Council for Excellence in Management and Leadership (CEML) (2001), Meeting the Need, Council for Excellence in Management and Leadership (CEML), London, consultation paper.

Delery, J., Doty, D. (1996), "Modes of theorizing in strategic human resources management: tests of universalistic, contingency, and configurational performance predictions", Academy of Management Journal, Vol. 39 No.4, pp.802-35.

Doyle, M. (1995), "Organisational transformation and renewal: a case for reframing management development?", Personnel Review, Vol. 24 No.6, pp.6-18.

Easterby-Smith, M., Thorpe, R., Lowe, A. (2002), Management Research, Sage, London.

Fairclough, N. (2005), "Discourse analysis in organization studies: the case for critical realism", Organization Studies, Vol. 26 No.6, pp.915-39.

Fiedler, F. (1996), "Research on leadership selection and training: one view of the future", Administrative Science Quarterly, Vol. 41 No.2, pp.241-51.

Francis, H. (2002), "The power of 'talk' in HRM based change", Personnel Review, Vol. 31 No.4, pp.432-48.

Fulmer, R., Wagner, S. (1999), "Leadership: lessons from the best", Training and Development, Vol. 53 No.3, pp.28-33.

Gratton, L., Hope Hailey, V., Stiles, P., Truss, C. (1999), Strategic Human Resource Management, Oxford University Press, Oxford.

Guest, D., King, Z. (2004), "Power, innovation and problem solving: the personnel managers' three steps to heaven?", Journal of Management Studies, Vol. 41 No.3, pp.401-23.

Hardingham, A. (1999), "Too close to home", Learning Centre, People Management, Vol. 5 No.17, pp.33.

Harrison, A. (2002), "Case study research", in Partington, D. (Eds),Essential Skills for Management Research, Sage, London, pp.158-80.

Hayes, J., Rose-Quirie, A., Allinson, C.W. (2000), "Senior managers' perceptions of the competencies they require for effective performance: implications for training and development", Personnel Review, Vol. 29 No.1, pp.92-105.

House, R., Aditya, R. (1997), "The social scientific study of leadership: quo vadis?", Journal of Management, Vol. 23 No.3, pp.409-73.

Johnson, P., Johnson, J. (2002), "Facilitating group cognitive mapping of core competencies", in Huff, S., Jenkins, M. (Eds), Mapping Strategic Knowledge, Sage Publications, London, pp.221-36. 
Kamoche, K. (2000), "Developing managers: the functional, the symbolic, the sacred and the profane", Organization Studies, Vol. 21 No.4, pp.747-74.

Lee, R. (1996), "What makes training pay", Issues in People Management, Chartered Institute of Personnel and Development, London, No. 11.

Mabey, C. (2002), "Mapping management development practice", Journal of Management Studies, Vol. 39 No.8, pp.1139-60.

Mabey, C. (2005), Management Development Works: The Evidence, Chartered Management Institute, London, executive summary.

Mabey, C., Thomson, A. (2000), "Management development in the UK: a provider and participant perspective", International Journal of Training and Development, Vol. 4 No.4, pp.272-86.

Meldrum, M., Atkinson, S. (1998), "Is management development fulfilling its organisational role?", Management Decision, Vol. 36 No.8, pp.528-32.

Miles, M., Huberman, M. (1994), Qualitative Data Analysis, Sage Publications, Thousand Oaks, CA.

Milliken, F., Morrison, E., Hewlin, P. (2003), "An exploratory study of employees' silence: issues that employees don't communicate upward and why", Journal of Management Studies, Vol. 40 No.6, pp.1454-76.

Mole, G. (1996), "The management training industry in the UK: an HRD director's critique", Human Resource Management Journal, Vol. 6 No.1, pp.19-26.

Murphy, D., Southey, G. (2003), "High performance work practices, perceived determinants of adoption and the role of the HR practitioner", Personnel Review, Vol. 32 No.1/2, pp.73-92.

Ogbonna, E., Whipp, R. (1999), "Strategy, culture and HRM: evidence from the UK food retailing sector", Human Resources Management Journal, Vol. 9 No.4, pp.75-90.

Partington, D. (2002), "Grounded theory", in Partington, D. (Eds), Essential Skills for Management Research, Sage, London, pp.136-57.

Pettigrew, A. (1990), "Longitudinal field research on change: theory and practice", Organization Science, Vol. 1 No.3, pp.267-92.

Preskill, H., Lackey, R. (1999), "The politics of program evaluation and the misuse of evaluation findings", paper presented at the Academy of Human Resource Development, Arlington, VA, March 3-7.

Purcell, J. (1999), "Best practice or best fit: chimera or cul-de-sac", Human Resource Management Journal, Vol. 9 No.3, pp.26-41.

Rainbird, H. (1994), "The changing role of the training function; a test for the integration of human resource and business strategy", Human Resources Management Journal, Vol. 5 No.1, pp.87-105.

Ready, D. (2004), "How to grow great leaders", Harvard Business Review, Vol. 82 No.12, pp.93-100.

Ready, D., Conger, J. (2003), "Why leadership development efforts fail", MIT Sloan Management Review, Vol. 44 No.3, pp.83-8.

Santos, A., Stuart, M. (2003), "Employee perceptions and their influence on training effectiveness", Human Resources Management Journal, Vol. 13 No.1, pp.27-45. 
Schafer, R., Dyer, L., Kilty, J., Amos, J., Ericksen, J. (2001), "Crafting a human resource strategy to foster organizational agility: a case study", Human Resources Management, Vol. 40 No.3, pp.197-211.

Schneider, B., Hayes, S., Lim, B., Raver, J., Godfrey, E., Huang, M., Nishi, L., Zeigert, J. (2003), "The human side of strategy: employee experiences of strategic alignment in a service organization", Organization Dynamics, Vol. 32 No.2, pp.122-41.

Schuler, R., Jackson, S.E. (1987), "Linking competitive strategies with human resource management practices", The Academy of Management Executive, Vol. 1 No.3, pp.207-19.

Sheehan, C. (2005), "A model for HRM strategic integration", Personnel Review, Vol. 34 No.2, pp.192-209.

Skinner, D., Mabey, C. (1997), "Managers' perceptions of strategic HR change", Personnel Review, Vol. 26 No.6, pp.467-84.

Sung, J., Quinn, M. (2005), CIPD Annual Survey Report, Training and Development, London.

Tate, W. (2004), "Linking development with business", in Storey, J. (Eds),Leadership in Organizations, Routledge, London, pp.293-318.

Thomson, A., Storey, J., Mabey, C., Gray, C., Farmer, E., Thomson, R. (1997), A Portrait of Management Development, Institute of Management, London.

Truss, C. (2001), "Complexities and controversies in linking HRM with organizational outcomes", Journal of Management Studies, Vol. 38 No.8, pp.1121-49.

Williams, S. (2001), "Upstream, downstream: the flow and stock of UK managers", Council for Excellence in Management and Leadership Report, Vol. July.

Wright, P., Snell, S. (1998), "Toward a unifying framework for exploring fit and flexibility in strategic human resource management", Academy of Management Review, Vol. 23 No.4, pp.756-72.

Zenger, J., Ulrich, D., Smallwood, N. (2000), "The new leadership development", Training and Development, Vol. 54 No.3, pp.22-7.

\section{Appendix. The survey questionnaire - main questions}

\section{MD strategy}

- Do you have a MD strategy for the development of business leaders and general managers? If Yes (Y) what is it? If No (N) why not?

- What drives the management development of business leaders and general managers in the business?

- Who has most influence on the management development agenda in your business and why?

\section{Leadership and GM development requirements}

- What do you see as the critical capabilities for successful leadership of this business now?

- In what way do you see these changing in the future? 


\section{Evaluation of current provision}

- What are the strengths of current BL and GM development provision in terms of: its effectivenes; adequacy of coverage; evidence of business impact; evidence of personal impact.

- Using the same criteria, what are the weaknesses of current BL and GM development?

- How could weaknesses be addressed?

\section{Future business challenges and MD implications}

- What do you see as the major challenges emerging in your business environment that will face leaders of the future?

- What implication do you think these have for leadership development required to meet these challenges?

- What implications do you think these have for effective MD strategy?

- What implications do you think these have for the focus and provision of MD activity?

\section{Questions/issues like to see research addressing}

- What are the questions about MD that you need to get answered to enable your business to enhance its future business leadership capability?

- What do you believe would need to be in place for you to have confidence that your business is building leaders to secure its future growth and survival?

\section{Management development experience}

- Please describe the process by which you came to have BL or GM development?

- Briefly describe what that development has involved?

- What development activities/events have had most personal impact? Why?

- What development activities/events have had least personal impact? Why?

- What development activities have had most business benefit? Why?

- What development activities have had least business benefit? Why? 